\title{
Por uma ética ambiental de inspiração vitalista
}

\author{
From an environmental ethics of vitalist inspiration
}

\author{
André Brayner de Farias*
}

Recebido em:10/2013

Aprovado em:10/2015

\begin{abstract}
Resumo: $O$ artigo propõe uma problematização da ética ambiental a partir da filosofia da natureza. Toda ética ambiental está fundamentada em uma determinada visão de natureza, em geral romântica e piedosa. Trata-se de reconhecer que a consideração moral não pode ser uma exclusividade do ser humano, ou seja, devemos reconhecer a dignidade moral dos outros animais e da natureza, entendida como conjunto dos elementos ainda não transformados pela cultura, conforme a clássica dicotomia natureza-cultura. A ética ambiental deve fazer a crítica do antropocentrismo, mas não necessita sacralizar a natureza. Tomamos a filosofia de Henri Bergson, sobretudo a obra Evolução criadora (1907) como referência para uma problematização da natureza. $O$ que pretendemos é uma visão de natureza orgânica, dinâmica, não romântica e não idealizada. A consequência dessa visão, que podemos chamar de vitalista, é que o ser humano e a cultura deixam de ser considerados elementos antagônicos da natureza. A ecologia e a ética ambiental podem agora ser pensadas como processos ou engajamentos culturais a favor de uma nova relação com a natureza, para além de uma visão meramente conservacionista e sacralizadora.
\end{abstract}

Palavras-chave: Ética ambiental, natureza, vitalismo, evolucão, cultura.

Abstract: The paper proposes a problematization of environmental ethics from the philosophy of nature. All environmental ethics is based on a determined vision of nature, in general romantic and pious. It is recognized that the moral consideration can not be a human exclusivity, in other words, we must recognize the moral dignity of other animals and nature, understood as a set of elements still unprocessed by culture as the classic dichotomy of nature - culture.

\footnotetext{
* Doutor em Filosofia PUCRS/UCS

Problemata: R. Intern. Fil. v.6, n. 3(2015), p 320-335 ISSN 2236-8612 doi:HTTP://dx.doi.org/10.7443/problemata.v6i3.17189
} 
Environmental ethics must criticize anthropocentrism, but it does not need to sacralize the nature. We take the philosophy of Henri Bergson, especially the book Creative evolution (1907) as a reference to an inquiry of nature. What we want is a vision of an organic nature, dynamic, not romantic and not idealized. The consequence of this view, we can call vitalist, is that the human being and culture is not longer considered to be antagonistic elements of nature. The ecology and environmental ethics can now be thought as a processes or cultural engagements in favor of a new relationship with nature, beyond a purely conservationist and sacralizadora vision.

Keywords: Environmental ethics, nature, vitalism, evolution, culture.

\section{Introdução}

Uma das dificuldades de tratar filosoficamente a questão ecológica diz respeito ao caráter de urgência implicado na problemática socioambiental. Sendo que é exatamente em nome da mesma urgência que parte da filosofia tem se mobilizado na direção da ecologia. A dificuldade se explica pela diferença de velocidade entre a especulação filosófica e a demanda dos impasses socioambientais: pois o pensamento filosófico exige uma certa maturação lenta das questões, mas nesse caso tais questões demandam soluções urgentes. Talvez essa impaciência se deva ao predomínio do discurso científico, de caráter pragmático: a sociedade espera soluções. No entanto, a filosofia não existe para dar soluções, e sim para qualificar o pensamento a respeito das questões, aprofundar a consciência do problema, o que não significa se alienar do discurso pragmático, muito pelo contrário, pois ao aprofundar a consciência do problema tornamos mais sério o espírito de urgência.

No campo da filosofia, duas áreas respondem muito enfaticamente à questão ecológica: a ética e a filosofia da natureza. A ética ambiental surge a partir da consciência do esgotamento da moralidade tradicional, basicamente antropocêntrica. A crítica do antropocentrismo vai merecer lugar de muita importância no discurso da ética ambiental. Dificilmente uma teoria ética autenticamente ambiental tomará o ser humano como centro absoluto de toda consideração moral. Talvez possamos dizer que o grande mérito da ética ambiental, tomada como campo discursivo, seja a consciência da necessidade de transcender $\mathrm{o}$ antropocentrismo, 
independentemente das diferenças de tonalidade, que são muitas, entre as correntes mais representativas dessa disciplina ${ }^{1}$.

A revalorização da filosofia da natureza parece ser sintoma do paradigma ecológico. Sabemos da antiguidade dessa disciplina, basta lembrar que a filosofia começa com a pergunta pela physis. E também sabemos que modernamente, pelo menos desde Galileu, a especulação filosófica sobre a natureza tendeu a ser substituída pelas fórmulas matemáticas e abstratas das ciências naturais, do que resultou todo aparato científico e técnico de manipulação, transformação e esgotamento dos recursos da chamada natureza. Contemporaneamente vemos ressurgir a discursão especulativa sobre o significado da natureza. Provavelmente porque percebemos que a natureza não se resolve nos cálculos da física, e também porque as disciplinas científicas da natureza chegaram a questões limítrofes, regiões conflituosas onde os domínios ora se ameaçam reciprocamente, ora se confundem, ora se transcendem. Mas para não se arriscar longe demais nas veredas das ciências, pensemos apenas na necessidade de ver a natureza com novas lentes e tomando novos enfoques. A filosofia da natureza ganha novo valor na era do paradigma ecológico.

Este artigo é uma experiência filosófica, um ensaio, que parte de dois campos discursivos, a filosofia da natureza e a ética, para gerar um terceiro, a ética ambiental. Nosso ponto de partida, a busca de uma nova visão de natureza, resulta da constatação de que predomina nos discursos ecológicos mais propalados e comentados uma ideia ingênua de natureza. Mas de uma ingenuidade nem sempre inocente, uma ingenuidade extremamente atenta, operante, de olho vivo no mercado de capitais. Outras vezes uma ingenuidade romântica, inocente, tendendo a sacralizar a natureza. São os ecologistas mais bem intencionados, engajados na causa de salvar o planeta da ação antrópica, (o que deveria implicar também em salvar o planeta de suas próprias ações). A nova ideia de natureza será buscada na filosofia de Bergson (Evolução criadora), tratando-se de entender: i. que a natureza é um processo aberto, em um permanente dinamismo dependente das múltiplas interações dos organismos; ii. que o ser humano com sua consciência expandida em liberdade e seu psiquismo inteligente é filho legítimo da natureza; e que, portanto, iii. qualquer visão não ingênua de natureza deve considerar o dinamismo da ação antrópica, não para justificar qualquer quadro de desequilíbrio e 
destruição, mas para pensar com nova consciência o sentido de nossa responsabilidade. A partir daí delineamos a ideia de uma ética ambiental que chamaremos de vitalista, uma vez que inspirada livremente no vitalismo filosófico de Henri Bergson.

Sobre a ideia de natureza desde uma perspectiva não linear da evolução

Certamente um grande mérito de Darwin foi mostrar que o homem é tão animal como qualquer outro animal da natureza. O pensamento evolucionista é, nesse sentido, um golpe contra o antropocentrismo. Ao mesmo tempo o animal mais inteligente da natureza está na ponta da lança da evolução, e o darwinismo não consegue escapar do modelo linear de interpretação da vida, herdeiro de Aristóteles. Por conta de uma tendência linear ou unilateral o evolucionismo de Darwin ao mesmo tempo em que desloca o ser humano do centro, posiciona-o na condição de mais evoluído. Se o evolucionismo não se presta para uma apropriação moral, dado que Darwin está analisando fenômenos da natureza, onde vigora um determinismo independente da construção deliberada e consciente de valores, no entanto ele está no fundo do argumento antropocêntrico que sustenta a supremacia ou a exclusividade da condição moral do ser humano.

Os defensores de uma ética para os animais acusam a tradição moral majoritária do ocidente de ser especista. O especismo é a posição que discrimina o valor moral dos animais conforme o grau evolutivo de sua espécie. O argumento do especista é semelhante ao do racista e do sexista: a diferença de espécie, de cor da pele e de sexo implicariam em diferença de valor moral. E da mesma forma como discriminar moralmente um indivíduo pela cor de sua pele ou pelo seu sexo é absurdo e arbitrário, discriminar pelo grau evolutivo da espécie também carece de fundamento. Obviamente que o especismo é anterior ao evolucionismo, provavelmente se confunde com a própria história do Homo sapiens, mas a teoria evolutiva fortalece a convicção de nossa superioridade moral, ao mesmo tempo em que abre perspectivas para o descentramento humano.

Um evolucionista não precisa ser necessariamente um especista, basta que ele consiga admitir para o fenômeno da vida um desenvolvimento não linear. 
O filósofo francês Henri Bergson (1859 - 1941) propõe em sua obra Evolução criadora (1907) um modelo de evolução que rompe com o esquema da linearidade. Bergson entende que a vida evolui não em uma única direção, mas tomando vias divergentes. $\mathrm{O}$ movimento da vida obedece a um princípio de diferenciação, que consiste na variação dos caminhos pelos quais a vida encontra saídas para expandir o seu fluxo. O princípio de diferenciação não obedece a uma finalidade dada a priori nem se reduz à teoria da adaptação darwiniana, que tende a uma explicação mecânica da interação entre organismo e meio. $O$ princípio da diferenciação e a ideia das linhas divergentes propostos por Bergson tem a dupla vantagem de fortalecer argumentos não especistas e de problematizar a ideia de natureza pelas consequências do desenvolvimento da inteligência. Essas vantagens interessam, como veremos, para o projeto de uma ética do meio ambiente.

Segundo Bergson, três são as direções fundamentais que a vida toma no processo evolutivo, são elas: o torpor vegetativo, o instinto e a inteligência. A vida ou, mais especificamente, o impulso vital é uma espécie de consciência que invade a matéria forçando-a a assumir as variadas formas dos seres vivos. Cada organismo é um resultado mais ou menos exitoso desse processo que é o movimento de expansão do impulso vital. A consciência está presente em toda forma de vida, embora na grande maioria permaneça adormecida, e tudo indica que ela está mais associada à função locomotora da vida animal. Quanto mais se complexifica a função locomotora, mais a consciência se expande.

Os vegetais tendem à fixação, produzindo e armazenando continuamente energia através do processo fotossintético. Os animais tendem ao movimento e desenvolvem dispositivos para assimilar a energia produzida pelas plantas e por outros organismos. A atividade animal vai se desenvolver em duas grandes vias, o instinto, que prevalece na vida invertebrada, e a inteligência, que evolui na direção dos vertebrados. $O$ mais importante a se notar nesse modelo de Bergson é o caráter divergente do movimento de expansão da vida: a inteligência não é a superação evolutiva do instinto, nem o instinto uma espécie inferior de inteligência, senão que instinto e inteligência configuram dois métodos distintos e eficientes de solução para os problemas da vida animal. São tendências da vida, e entre elas vigora uma diferença de natureza e não apenas de grau: o 
esquema tradicional, linear, não reconhece a importância da diferença de natureza porque se acostumou a ver na evolução da vida apenas uma graduação que se desdobra dos vegetais até a vida inteligente.

O processo de diferenciação é uma seleção de tendências que diferem por natureza: a via dos invertebrados é adequada para o desenvolvimento instintivo, que chega a seu ápice nos insetos himenópteros, formigas e abelhas; a via dos vertebrados é adequada para o desenvolvimento da inteligência, que chega a seu ápice no ser humano. Mas a diferenciação não exclui a outra tendência, ainda que selecione e privilegie o desenvolvimento de uma delas. Obviamente que não deixamos de ser instintivos porque nos tornamos inteligentes, aliás, o instinto permanece sendo a grande força de sustentação da vida.

Mas importa saber em que o instinto difere da inteligência. $\mathrm{O}$ que há em cada tendência que só se observa nela? A consciência encontra na rota dos vertebrados, os animais que desenvolvem o sistema cérebro-espinhal, um caminho mais livre para se expandir, que proporcionará formas de vida cada vez mais capazes de selecionar e fazer escolhas. Tudo indica que a consciência deseja encontrar a máxima liberdade possível ou proporcionar a forma de vida mais apta a selecionar e deliberar. Essa observação da consciência sinaliza a diferença mais visível e reconhecida entre instinto e inteligência: o gesto instintivo é mais automático, como se só pudesse ter aquela direção enquanto que o gesto inteligente é mais seletivo porque consegue dispor de uma variação de alternativas; o instinto é um movimento espontâneo, de consciência entorpecida, a inteligência é um movimento calculado, de consciência desperta. $\mathrm{O}$ animal basicamente instintivo obedece ao ritmo da natureza; o animal inteligente tende a imprimir o seu próprio ritmo ao da natureza, tentando imitar, mas criando novidade. $\mathrm{O}$ instinto não surpreende a natureza, a inteligência sim. A natureza contém o instinto, a inteligência expressa a vontade de conter a natureza. ${ }^{2}$

O protótipo da vida instintiva é o formigueiro e a colmeia. Nessas sociedades vigora uma ordem perfeita na medida em que toda ação é internamente regulada e como que orientada para dentro: o indivíduo vive em função de sua comunidade e, dessa forma, a individualidade não tem sentido. Não existe liberdade porque a ação é programada e determinada naturalmente. Não há distinção significativa entre um formigueiro e outro da 
mesma espécie de formiga, a não ser alguma variação devida a circunstâncias ambientais.

O protótipo da inteligência é, obviamente, a vida humana. Em nossas sociedades a ordem está bem distante da perfeição e ela só é aproximadamente conquistada através de dispositivos regulatórios que devem ser internalizados: o indivíduo não vive espontaneamente em função do grupo, ele precisa aprender a conviver e tal processo é variável em cada sociedade e entre sociedades. A complexidade da vida inteligente se deve ao alcance da liberdade, proporcional ao nível de abertura da consciência. Como a possibilidade de escolha é larga, o critério tende a favorecer o próprio indivíduo: a liberdade acena para a individualidade. O grande desafio da sociedade humana é a conjugação das liberdades.

Duas forças antagônicas estão implicadas na vida social dos humanos: a força da coesão social e a força da liberdade; a pressão externa para manter o vínculo com o grupo e a pressão interna, individual, para manter o vínculo apenas consigo mesmo. $\mathrm{O}$ equilíbrio entre essas duas forças quase nunca é satisfatório, pois os indivíduos devem se contentar com limites estreitos para o exercício de suas liberdades.

Tal interpretação vitalista da inteligência e da vida social dos seres inteligentes permite superar certos impasses de nossa relação com a natureza. No fundo de toda ética ambiental palpita uma determinada concepção de natureza. O exame da crise ecológica, em geral, leva ao entendimento de que a atividade humana é quase que necessariamente predatória e que a natureza para ser salva precisa ser isolada e protegida da sociedade humana. Porém, tal análise só parece possível se desconsiderar o fato de que a vida inteligente é filha legítima da natureza. Temos que admitir como natural o princípio inteligente de negação do determinismo natural. Obviamente que tal consideração não sinaliza nenhuma possibilidade de justificativa moral do prejuízo que a humanidade inteligente tem causado ao chamado mundo natural. Trata-se, antes, de atualizar a nossa concepção de natureza, ainda demasiadamente herdeira de uma modernidade que primeiramente objetifica e instrumentaliza para, posteriormente e após haver se ressentido, idealizar e romantizar. O pensamento ecológico contemporâneo ainda padece de um certo romantismo ressentido da modernidade.

Uma ética ambiental não pode carregar tal ressentimento, não pode ter pena da natureza, porque esta natureza merecedora

Problemata: R. Intern. Fil. v.6, n. 3(2015), p 320-335 ISSN 2236-8612 
de piedade pode deixar de existir se recuperarmos uma relação mais autêntica com a nossa natureza (interior e exterior). Para tanto devemos formar outro imaginário da natureza, porque o que temos não nos serve, seja porque violentamos, seja porque sacralizamos. Precisamos formar outro imaginário da natureza para nos livrar do hábito quase automático de consumir a natureza na produção de utilitários e também do mito da natureza intocada, de que nos fala Antônio Carlos Diégues. O hábito e o mito se retroalimentam e se autoiludem. $\mathrm{O}$ resultado de tal ilusão é que tendemos a conceber éticas ambientais pregadoras de um retorno mítico à vida selvagem, por um lado, e por outro a escapar para versões sofisticadas e onerosas de desenvolvimento sustentável, ambas alternativas pouco viáveis e pouco efetivas. O desenvolvimento sustentável não consegue frear a voracidade consumista do mundo globalizado, aliás tem se sustentado da mesma voracidade e da mesma saciedade insuficiente e também tem produzido boas relações com as propostas de retorno mítico, (veja-se o mercado ecológico e sua oferta de opções de viagens para os paraísos ecológicos protegidos ao redor do planeta).

A natureza é algo que contem em si o princípio de sua mutação. Os seres vivos são as unidades indivisíveis indissociáveis desse todo orgânico e profundamente dinâmico que representam a luta perpétua do impulso vital para fazer durar a matéria viva do planeta.

A natureza é o conjunto das infindáveis estratégias de sobrevivência do impulso vital, é o movimento único da vida que se estende em diversas direções em busca da saída mais sofisticada para os problemas que vão surgindo na medida em que a vida inventa e reinventa suas formas. A força íntima e fundamental da vida é o instinto, por conta dele a natureza mantem a sua perenidade e o seu vigor. Mas o instinto é repetitivo porque sua consciência é dormente. É pela via da inteligência que a natureza encontra as formas mais adequadas para a sua própria reinvenção, para sua diversificação. O ser humano é o salto mais ousado e mais arriscado do impulso vital, porque é através dele que a consciência desperta plenamente, a ponto de escapar do determinismo e forjar as suas próprias condições. A liberdade é o maior risco da vida e o seu maior achado, seu mais precioso tesouro. A natureza, ao criar condições para a vida inteligente e livre abre para si um campo variado de possibilidades. 
A cultura não é a negação da natureza, mas a sua diferenciação, o reencontro de seu próprio princípio de criação.

\section{Ética ambiental - uma proposta vitalista}

A expansão inteligente e humana da consciência é abertura da natureza para futuro indeterminado. $O$ princípio da temporalidade histórica foi introduzido na natureza, mas por ela própria. A mesma ciência ecológica que reage politicamente à apropriação da natureza pela cultura, abrindo espaço para as propostas de retorno mítico, admite pelo paradigma da interação dos elementos a continuidade entre a história natural e a história humana. A consciência humana expandida em liberdade é o ponto de abertura da natureza para fora de seu determinismo. $\mathrm{O}$ destino antiecológico da humanidade não é inevitável, é apenas uma entre tantas outras possibilidades igualmente corrigíveis ou aperfeiçoáveis pelo mesmo princípio de abertura e de diferenciação que a consciência expandida da inteligência pressupõe.

Escapar ao determinismo implica em assumir a responsabilidade de seu próprio destino liberado. Cabe à ética ambiental problematizar a fatalidade de tal destino e isto implica em repropor a relação entre liberdade e responsabilidade. ${ }^{3} \mathrm{O}$ desafio do paradigma ecológico é converter a cultura em campo de problematização ética, começando pela tomada de consciência de nossa responsabilidade de existir culturalmente.

Qual o sentido da cultura? Por que produzimos artefatos? $\mathrm{O}$ que fazemos quando transformamos as coisas naturais em utilitários? A resposta óbvia e imediata é que essa é a forma como damos conta de sobreviver e reproduzir. Produzimos objetos porque não estamos determinados pelas coisas que nos rodeiam e porque já temos necessidades que exigem a invenção de objetos, que por sua vez despertarão novas necessidades que levarão a novas invenções. Produzimos cultura porque somos livres e para que possamos sê-lo ainda mais. É provável que seja este o sentido da cultura: a liberdade. ${ }^{4}$

Mas Também produzimos objetos para nos habituar a eles, e não estamos falando apenas em coisas materiais, pois, obviamente, também faz parte da cultura a criação de ideias e crenças. Uma cultura não teria sentido se não quisesse se manter, ser transmitida, gerar valores que transformamos em 
bens herdáveis. Toda cultura tende a virar tradição, que desejará se perpetuar produzindo inclusive crenças e ideologias a favor de sua conservação. Com o tempo, aquilo que significou conquista de liberdade pode vir a significar exatamente o contrário, pois nada impede ninguém de querer viver de maneira avessa a sua própria cultura. Nada impede ninguém de desejar trair, em nome de sua própria liberdade, a sua tradição cultural. A cultura vive da consagração do hábito e a moral do hábito tende a gerar um novo determinismo e, consequentemente, a minar o espaço da liberdade. Mas, se aceitamos que o sentido de nossa existência cultural é a liberdade, somos eticamente convocados a superar o determinismo dos nossos próprios hábitos.

A crise ecológica é certamente um reflexo de nossa crise cultural. Não é difícil compreender que o esgotamento dos recursos naturais revela a saturação de nossos hábitos e a necessidade urgente de mudança em nossos padrões de comportamento. A análise de tal fenômeno é difícil, pois tende a se estender em diversas direções, não respeitando fronteiras, por isso não é exagero tratar a questão ambiental como mudança de paradigma. A ecologia solicita uma nova visão da natureza: orgânica, não mecanicista, não utilitária; um novo entendimento de nossa relação com a natureza: responsável, solidário, não objetificante; uma nova cultura, que não se contente em mudar hábitos a partir de um jogo onde as cartas já estão marcadas, que não seja simplesmente a conversão para uma economia verde onde nos contentaríamos em ser consumidores ecologicamente conscientes, mas uma cultura nascida da superação da esgotada dicotomia entre natureza e cultura. Uma cultura, enfim, que leve adiante o impulso criador da vida, o que demanda uma visão integrada da natureza e uma relação responsável e solidária com o ser vivo.

O caminho que tomamos até aqui, que situa a expansão da consciência humana no quadro geral da evolução da vida, nos permite conceber a ética em coextensão à vida. Isto não implica numa visão naturalista da ética, pois se desenvolvemos biologicamente um psiquismo capaz de ação refletida e livre significa que nossas ações são indetermináveis, não são controláveis pela natureza, somos capazes de surpreender a nós mesmos e à natureza, somos capazes de objetificar a árvore em madeira e o rio em hidrelétrica. Conceber a ética em coextensão à vida é afirmar o movimento da vida na nossa condição ética, 
como se o drama ético da vida representasse o seu próprio movimento criador, poético, no sentido da poiésis, ${ }^{5}$ como se a expansão do impulso vital continuasse forçando a vida, introduzindo através do ser humano a temporalidade na natureza, a abertura para o futuro, aquilo que não se pode prever. Exatamente porque somos livres, ou seja, capazes de causar surpresa, inventamos a moral, ou seja, aquilo que vai nos determinar a agir corretamente, o que quer dizer sem causar surpresa. Os valores morais são como artefatos que inventamos, e eles prescrevem, se tornam velhos e inoperantes, substituíveis como qualquer outro artefato. Por isso o mais importante é fazer da vida moral uma vida ética. Quero dizer que devemos afirmar a nossa capacidade de criação de mundo, que pressupõe a consciência aguda e atenta do nosso condicionamento moral. Voltamos assim ao problema do hábito, essa força de repetição da vida: fazer da vida moral uma vida ética é enfrentar a força do hábito, desviar da repetição, se convocar para a criação de si mesmo e do mundo.

Ao encontro dessa perspectiva, uma ética para o meio ambiente se compromete com uma concepção aberta de ecologia $^{6}$, de natureza e de cultura. O pensamento ecológico deve ser variado da predominância científica e ser vitalizado por uma filosofia intuitiva, ao estilo bergsoniano, capaz de elaborar um novo imaginário da natureza. Uma ecologia contaminada por tal filosofia devolve à natureza a sua organicidade, altamente prejudicada por uma visão majoritariamente científica e tecnológica. ${ }^{7}$ Uma ecologia filosófica, sem deixar de ser científica, pode ultrapassar o impasse da dicotomia entre natureza e cultura, elevar tanto a noção de cultura para além do mero impulso fabricador e utilitário, favorável à vida mas não suficiente enquanto modelo de psiquismo, quanto elevar a noção de natureza para além do esquematismo geométrico cartesiano, base metafísica da objetificação técnica, e para além da sacralização romântica e ressentida que norteia o pensamento e o movimento ecológico que em nada ameaçam o modelo econômico e exploratório da vida no mundo contemporâneo, no máximo lhe investe de sentimento culposo que deverá gerar medidas compensatórias de conservação da natureza pretensamente intocada.

Uma ética para o meio ambiente afirma uma noção de cultura não antagônica mas solidária à noção de natureza, porque parte de uma perspectiva orgânica e não mecanicista de

Problemata: R. Intern. Fil. v.6, n. 3(2015), p 320-335 ISSN 2236-8612 
natureza, ou seja, uma natureza que gera e abriga o conceito de cultura.

Está em questão a recuperação de um dinamismo afirmativo e criador da vida, que corresponderia a um modelo vitalista de ética ambiental.

O pensamento ecológico majoritário é predominantemente conservacionista e preservacionista, calcado, portanto, na ideia de que a natureza deve ser conservada ou preservada e, para tanto isolada da população humana. Uma ética para o meio ambiente de cunho vitalista não pode se alimentar do mito da natureza intocada e não pode se contentar com o reducionismo de uma ecologia científica e matemática, que retém da natureza apenas aquilo que pode ser previsto para que possa ser dominado, não fazendo diferença se para o bem ou para o mal. Não se trata de pregar o retorno mítico a um estado inexistente e artificial de natureza, mas de reafirmar o estado criador da natureza assumindo a cultura como movimento ético. $\mathrm{O}$ problema da sustentabilidade da vida na Terra é mais radical do que supõem as fórmulas abstratas da ciência ecológica.

Um outro olhar se impõe, não protecionista, não temeroso, não reativo; um outro modo de relação precisa surgir, sensível, solidário e responsável pela vida e pelo ser vivo.

Criar valores que potencializem um novo olhar sobre a natureza e a cultura e uma nova relação de solidariedade com a vida é o desafio que se impõe a uma ética ambiental de inspiração vitalista.

\section{Conclusãa}

O liberalismo econômico foi, em parte, responsável por gerar o conceito vicioso e enganoso de liberdade que vigora nas sociedades modernas e civilizadas. Já temos bastante experiência e recursos suficientes para perceber que a cultura tem oprimido a vida muito mais do que liberado. É mais que urgente repensar o que entendemos por cultura.

Mas parece que é inevitável a naturalização da cultura, e até compreensível. Não saberíamos viver sem a proteção dos nossos hábitos. Não suportamos viver ao sabor das determinações da natureza, precisamos criar e elaborar nossas próprias determinações. Mas é preciso acolher e compreender também o movimento que contraria o determinismo do hábito. 
Essa tendência de contracorrente não é majoritária, é menor, quase imperceptível porque, em geral, é de caráter individual. Não é da sociedade contrariar o hábito, é do indivíduo. E o grande desafio é tornar essa tendência contagiante: mover a sociedade em contracorrente. Diz Bergson que essa é a função da filosofia: contrariar o hábito do pensamento, dominado pela inteligência fabricadora. Esse é o caminho que deve tomar toda ética, e mais estritamente a ética ambiental, enquanto ainda houver necessidade de diferenciar as disciplinas.

A dicotomia cultura-natureza está viciada, não responde mais aos problemas que temos pela frente. Talvez seja mais útil e pragmático pensar a cultura como desdobramento da natureza. Mas desdobramento não espontâneo, não dormente e sim consciente e respondente. Cultura como lugar de criação e renovação da natureza. Parece ousado e arriscado, mas nunca foi sem risco a expansão do impulso criador da vida. Quando nos acomodamos em nossos hábitos, culturalizados ou naturalizados, abandonamos a zona de perigo, produzimos e reproduzimos um estilo de vida conservador (e conservacionista).

O que se pretende com a ética ambiental, nessa inspiração bergsoniana, não é a afirmação inconsequente da cultura e da civilização devoradoras da natureza, mas uma retomada do impulso criador no núcleo mesmo da existência cultural, uma conversão ética da cultura. O que significa, em síntese, uma nova valorização da liberdade e da responsabilidade através de uma confiança não cega na indeterminação do futuro. Afirmar a nossa condição ética: selecionar, deliberar e responder, enfim, decidir.

\section{Referências}

BERGSON, Henri. A evolução criadora. Lisboa: Edições 70, 2001.

DERRIDA, Jacques. O animal que logo sou. São Paulo: Ed. UNESP, 2002.

DIÉGUES, Antônio Carlos. $O$ mito moderno da natureza intocada. São Paulo: Editora HUCITEC, 1996.

FELIPE, Sônia T. Antropocentrismo, sencientismo $e$ biocentrismo: perspectivas éticas abolicionistas, bem-estaristas e 
conservadoras e o estatuto de animais não-humanos. Em: Revista Páginas de Filosofia, v.1, n.1, jan-ju1/2009.

FLUSSER, Vilém. Natural:mente - vários acessos ao significado de natureza. São Paulo: Annablume, 2011.

GODOY, Ana. A menor das ecologias. São Paulo: EDUSP, 2008.

GUATTARI, Félix. As três ecologias. 6. ed. Campinas: Papirus, 1997.

JONAS, Hans. O princípio responsabilidade - ensaio de uma ética para a civilização tecnológica. Rio de Janeiro: Contraponto, Ed. PUC-Rio, 2006.

LATOUR, Bruno. Políticas da natureza - como fazer ciência na democracia. Bauru: EDUSC, 2004.

LEFF, Enrique. Discursos sustentáveis. São Paulo: Ed. Cortez, 2010.

NOBRE, Marcos; AMAZONAS, Maurício de Carvalho (orgs.). Desenvolvimento sustentável - a institucionalização de um conceito. Brasília: Ed. IBAMA, 2002.

SERRES, Michel. O contrato natural. Lisboa: Instituto Piaget, 1994.

SINGER, Peter. Ética prática. 3.ed. São Paulo: Martins Fontes, 2002

SOUZA, Ricardo Timm de. Alteridade e Ecologia. Em: Totalidade e desagregação - sobre as fronteiras do pensamento e suas alternativas. Porto Alegre: EDIPUCRS, 1996.

\footnotetext{
${ }^{I}$ Ver os artigos: FELIPE, S. T. Da considerabilidade moral dos seres vivos: a bioética ambiental de Kenneth E. Goodpaster; FELIPE, S. T. Valor inerente e vulnerabilidade: critérios éticos não-especistas na perspectiva de Tom Regan; ALMEIDA, J. A. M. de. A ética ambiental de Tom Regan: crítica, conceitos, argumentos e propostas; NEGRÃO, S. L. O critério da vida para uma ética ambiental: concepção, filiação, conceitos, argumentos e propostas de Kenneth Goodpaster; FAHRI NETO, L. O ambientalismo liberal considerado a partir de uma perspectiva ética; SALLES, P. B. de. Libertarianismo e socialismo: limites e possibilidades de uma ética ambiental; RODRIGUES, R. C. O ambientalismo liberal e as exigências conceituais de uma ética genuinamente ambiental. Todos publicados em ETHIC@ - REVISTA Internacional de Filosofia, da UFSC.

${ }^{2}$ Bergson tem várias formas de distinguir as duas tendências da vida animal, numa delas diz que o instinto é a capacidade de fabricar e utilizar instrumentos organizados e a inteligência é a capacidade de fabricar $e$ utilizar instrumentos inorganizados (Ver BERGSON, 2001. p. 131). O
} 
instrumento do animal instintivo é o corpo do organismo, pinças, antenas, garras; o instrumento do animal inteligente são coisas tomadas da natureza $e$ transformadas pela intenção do indivíduo. $O$ instintivo fabrica um instrumento de função limitada e, em geral, exclusiva a um ponto determinado da natureza e o tipo de ação que tal instrumento proporciona cumpre perfeitamente o seu objetivo; o inteligente fabrica um instrumento de ação ilimitada, aplicável em diversas circunstâncias, porém o instrumento nunca cumpre com perfeição o seu objetivo, o que leva o organismo a querer aperfeiçoar o aparelho inventado. O instinto é repetitivo, a inteligência é inventiva, capaz de variação.

${ }^{3}$ O princípio responsabilidade de Hans Jonas é um exemplo de esforço nessa direção, focalizado na crítica da civilização tecnológica.

${ }^{4}$ Uma indicação para essa linha de interpretação encontramos em Vilém Flusser: "No fundo, o que é bom é apenas a liberdade. As coisas são boas apenas na medida em que contribuem para me libertar. E isto é exatamente também a medida da cultura. Tecnologia não é cultura. E tecnocracia (governo da tecnologia não controlado) é anticultura. Em suma: cultura é tecnologia mais liberdade." FLUSSER, V. Natural:mente - vários acessos ao significado de natureza. São Paulo: Annablume, 2011. p. 55.

5 Conceito da filosofia antiga que expressa a potência ou capacidade humana da criação, típica dos poetas, mas não restrita a estes.

${ }^{6} \mathrm{O}$ conceito de ecologia menor proposto por Ana Godoy é muito apropriado para uma ética ambiental afirmativa da vida enquanto psiquismo criador. A autora contrapõe à ecologia maior, esta que encontramos nos compêndios científicos e que domina as políticas voltadas para a natureza, quase que invariavelmente de caráter conservacionista e territorialista, a ecologia menor, que libera a vida das fórmulas abstratas da ciência porque parte do entendimento de que a vida é estado de criação que compõe a sua própria ecologia (menor) reinventando-se constantemente.

${ }^{7}$ A ética ambiental aqui proposta não é do tipo que teme a tecnologia, é diferente, portanto, da proposta de Hans Jonas, baseada na chamada heurística do temor. A responsabilidade não precisa estar associada ao medo do que a tecnologia pode causar. Jonas tem razão a respeito do fato de que produzimos tecnologia tão complexa que as consequências desastrosas são cada vez mais prováveis, e que, portanto, a civilização tecnológica deve estar calcada no princípio da responsabilidade. Isto é absolutamente incontornável. Mas a responsabilidade não precisa ser uma relação movida pelo temor do que pode acontecer. Uma ética ambiental de estilo vitalista, como a que estamos propondo, concebe a responsabilidade como o ato livre da vida inteligente, afirmativo e não reativo, portanto não temeroso. $O$ temor enfraquece a consciência, embora provenha dela, pois a zona de possíveis que a consciência ilumina produz hesitação e pode levar a paralisar a ação. Obviamente que o medo tem uma função vital fundamental, mas a vida não evolui sem boa dose de risco. A responsabilidade deve ser afirmativa e livre e não reativa ou condicionada pelo temor do que pode acontecer, ela não pode ser sinônima da hesitação, que é uma fraqueza da consciência. Não pode haver liberdade autêntica sem responsabilidade. Mas também, não temer a tecnologia não significa ser cegamente confiante em nosso destino tecnológico, que se não é feliz não é por conta da tecnologia em si mesma,

Problemata: R. Intern. Fil. v.6, n. 3(2015), p 320-335 ISSN 2236-8612 
mas da relação de dependência que temos inventado com ela e que tem escravizado as pessoas seja pelo acesso seja pela exclusão. O princípio da responsabilidade é o mesmo da liberdade, ele não tem saída, a não ser acolher o que pode acontecer, assumindo o risco. Temer a tecnologia não é o mesmo que rejeitar a relação de dependência que tem minado o campo da civilização tecnológica para as boas condições de sustentabilidade da vida. 